covered; that we shall transform acids into lemon or orange-ades or into "shrub" drinks; that we shall salt oily substances and not sweeten salty ones: that we shall respect idiosyncracies; that when a taste camnot be covered, we shall not try to mix it, but shall rely on rinsing out the mouth or establishing a pleasant aftertaste."

D. M. MOIR, M.A., M.в.

\section{OBSTETRICS AND GYNAECOLOGY.}

On Posterion-Occipital positions of the Fetal Head. (American Practitioner and News).-Stewart suggests the following points of manaigement. Should the position be diagnosed early, before rupture of the membranes, the object to be attained is engagement of the head in the flexed condition. To attain this bring the dorsum of the child forward by abdominal manipulation. If the head be disengaged the position is at once changed to occipito-anterior, but if engaged the rotation of the trunk alone and its retention in this position, he considers, a strong factor in promoting the subsequent rotation of the vertex. Should dilatation of the cervix be well advanced and the anterior fontanelle low, the artificial rotation of occiput is to be assisted by pressing in front the fontanelle with two fingers in the vagina (thus promoting flexion) and at the same time pushing the sinciput backward; in some cases he has succeeded by the introduction of the whole hand into the vagina, in grasping the occiput and bringing it forward. If the labour be far advanced and the head arrived extended at the pelvic floor, axis-traction forceps are to be applied and a combined traction and flexion exercised. This is to be attained by lifting the application handles of the instrument well forward, and at the same time pulling the head in the direction of its long axis, a procedure which necessitates the wide separation of the traction rods from the shanks. The forceps are thus converted into a lever of that class in which the power is between the weight and the fulcrum. The shanks held well forward in the one hand, represent the fulcrum; the child's head between the blades, the weight, and the other hand of the operator acting through the traction rods, the power.

Diagnosis and Treatment of Rupture of THE Uterus. (B. M. J.).-Ludwig insists on the valuelessness of individual symptoms, such as collapse, bleeding, sudden and severe pain, recession of the formerly fixed presenting part, cessation of pains, \&c. He has found the best diagnostic signs to be: (1) in lateral rupture the interruption of the natural contour of the uterine quadrant, either a projection or a nodule being formed; (2) abnormal mobility of the uterus, and (3) emphysematous crackling at the seat of rupture. If the head presents and can be $p$ ushed back, bimanual examination under deep narcosis should lead to a certain diagnosis. With regard to treatment, delivery may be effected per vias naturales or by laparotomy. The former is indicated when a large part of the child is already fixed in the pelvis, and also when the diagnosis of uterine rupture cannot be made for certain before delivery. In cases in which the child remains in the uterus after the rupture or has only partially passed into the abdominal cavity, delivery $p e r$ vaginum is only to be preferred when it can be carried out without losing time or increasing or complicating the tear-for instance in head presentations and the absence of contraction of the pelvis, also where rupture takes place during an operation. Laparotomy is indicated when the whole child has passed into the abdominal cavity, when the passages are not fully dilated, in contracted pelvis, in severe hæmorrhages, and in injuries to the neighbouring organs. In partial passage of the child into the abdomen or with a living child still in the uterus, Casarean section is the correct procedure when natural delivery would take too long and be fraught with danger to the mother. As regards treatment after delivery of Ludwig's nine casesthree came into the hospital and were operated on-two by supra-vaginal amputation, and one by abdominal hysterectomy; all recovered. The remaining six were treated outside-five were operated on, four by supravaginal amputation, one by abdominal hysterectomyof which one recovered and four died of sepsis. 'There was no death from hæmorrhages except in the remaining ease which was not subjected to operative interference.

Abortion an d Quinine. (B. M.J.).--Schwab in seven cases of retained placenta after abortion gave a gramme of quinine divided into two "cachets" at ten minutes' interval $-7 \frac{7}{10}$ grs. at a dose. The results were encouraging. As a rule, the placenta was expelled in four hours and a half by the stimulation of the uterine muscular fibres caused by the drug. In sereral instan ces the pains had ceased for hours. Hence the action of quinine was positive. No bad results were observed and no tetanic contractions occurred.

Eclampsia. (American Journal of Obstetrics).-J. C. Edgar prefers chloroform, veratrum viride and chloral, in the order named, for the control of the convulsions. He believed that morphine prolongs the post-eclamptic stupor and interferes with eliminative processes. If the pulse is strong and rapid, veratrum viride is the most certain means for controlling convulsions. When the pulse is weak he employs morphine hypodermically, chloroform by inhalation, and chloral by rectum, with stimulation, if necessary. He considers rapid manual dilatation of the os and subsequent extraction of the 
foetus advisable as a rule; but if the internal os has disappeared and the external remains rigid, while the labour must be rapidly terminated, he favours four clean incisions from the edge of the os to the utero-vaginal junction. In performing manual dilatation, if the cervix is unyielding, a cervical dilator of gauze or a hydrostatic bag should be used until a slight relaxation of the cervix occurs. In the meantime veratrum viride is most valuable to reduce pulse rate and temperature, relax the cervix and cause prompt diaphoresis and diuresis. The child should not be extracted before the external os is completely dilated and paralyzed as rupture of the lower uterine segment or death of the child may occur. The ordinary methods of increasing the action of the eliminative organs are ardvised. As a diuretic, nitroglycerine is preferred to veratrum viride, and for diaphoresis, the hot-air bath to the hot pack. Edgar has found inhalation of oxygen of great value as a general stimulant, to aid elimination from the lungs and to prolong life during the stage of coma.

KEDARNATH DAS, M.D.

\section{甘ital statistics it somitation.}

\section{RESOLUTION ON THE REPORT OF THE LAHORE AND DELHI LUNATIC ASYLUMS FOR THE YEAR 1896.}

\section{(Continued from page 279 .)}

3. Judging from the figures quoted on the margin* which Paragraphs 19 to 24 . give the daily average strength of cri* 1892 Paraph 19 to $49 \cdot 50$ minal lunatics in the Lahore Âsylum for $1893 \ldots \quad . .55 \cdot 38$ each of the past five years, it would $1894 . . \quad \quad \because 61 \cdot 20$ apear that this class of patient is stead$\begin{array}{ll}1895 & . .\end{array} \quad .60 \cdot 50$ ily, if almost imperceptibly, on the $1896 \ldots \quad . .61 \cdot 24$ increase. They now number nearly one quarter of the population of the Asylum. The total population in the Lahore Asylum of lunatics tried and acquitted on the ground of insanity was 13 in 1893, 17 in 1894, 13 in 1895, and 18 in 1896. A difficulty having been experienced in properly supervising the criminal lunatics owing among other causes to structural defects in the present Asylum buildings, an extra expenditure for warders has been sanctioned as a temporary measure pending the decision that may be arrived at in respect to the proposed new Central Asylum. The criminal population of the Delhi Asylum remains of much the same strength as in former years, and criminals constitute less than one-ninth of the population of this Asylum.

t. The year under review was a healthier one for the Lahore Asylum than it has recently enParagraphs $37,38, \quad$ joyed. There was no special visitation
and 42 to 44. and 42 to 44 .

$+1894$

1895

517

in 1895. There were fewer admissions 492 into hospital t than in these two years, and the death-rate per cent. of daily average strength fell to $7 \cdot 66$, or $4 \cdot 22$ less
than the avera of $11 \cdot 85$ for the past ten years. The general healthiness of the year and the absence of epidemics among the general population of the country likely to effect the inmates of the Asylum may have had a great deal to do with this favourable state of things. At the same time it seems only reasonable to suppose that the greater care shown for the confort of the lunatics in providing them with an extra meal and a warm jersey may have played a not unimportant part in the general improvement in health. As regards the continued prevalence of bowel complaints, which has been attributed to the propensity of lunatics to eat the earth in the walls and floors, it was suggested in the review on the Report for the year 1895 that perhaps special arrangements could be made to prevent this. It is now reported that the practice is so exceedingly common among insanes that to segregate them so as to prevent them from getting at earth is practically impossible. It appears to the LieutenantGovernor that much depends on the character of the Asylum buildings. In preparing the plans for the proposed new Asylum the desirability of furnishing a certain number of cells with pakka floors and walls pakka up to a certain height should be borne in mind, as this is probably the only effectual means of checking the unwholesome habit.

5. At the commencement of the year 1896 there were 108 inmates (80 males, 28 females) in the Paragraphs 12 to Delhi Asylum; at the end of the year 18,39 to 41 and 45 . there were 126 (92 males, 34 females), $+1894 \quad$ giving an increase of 18. The total popu$\begin{array}{llll}1895 & \cdots & 163 & \text { the same as in the two previous years. }\end{array}$ $1896 \quad 161 \quad$ The daily average strength for these years was $105^{\circ} 14,111^{\circ} 23$ and $118^{\circ} \cdot 22$, respectively, against an average daily strength of 98.86 for the past ten years. But here agrain, as in the case of the Lahore Asylum and for similar reason, the year under review was an unusually healthy one. Indeed it was exceedingly so, there having been but 4 deaths, giving a death-rate of $3 \cdot 39$ per cent. only of the daily average strength against $9 \cdot 88$ for 1895 and an average of 11.82 for the previous decade. The death-rate of 3.39 is worthy of notice as being the smallest ever recorded. The percentage of cures to daily strength was, however, considerably less than in the year 1895 and in the previous decade, the figures being $10 \cdot 15$ for $1896,17 \cdot 98$ for 1895 and $19 \cdot 32$ for past ten years. It would be interesting to know whether any reasons can be assigned for the low percentage of the year under review, and this subject should have been discussed in the Report. Prima facie the year having been so very healthy a higher percentage of recoveries might have been anticipated from the healthy influences of the body on the mind.

6. Mr. Mackworth Young regrets to find that the reports Paragraphs 25 to in respect to watch and ward are still un27 and 55 and 56. $\quad \begin{aligned} & \text { satisfactory. An explanation should be } \\ & \text { furnished showing how it was that the }\end{aligned}$ criminal lunatic who escaped from the Lahore Asylum during the night was not missed until the early morning. The escape of three criminal lunatics from the Delhi Asylum can only be characterised as extremely unsatisfactory, and the Lieutenant Governor will be glad to have detailed reports as to the manner in which these escapes were effected. It is to be feared that neither of the two Asylums is sufficiently secure to provide against the escape of that more astute type of lunatic to which criminals, classed as insane by the Courts, not infrequently belong. His Honor observes that it is stated that the warders concerned were severely punished. $\mathrm{He}$ would be glad to know to what extent each one was responsible, and the punishment inflicted in each case.

7. In both Asylums there was considerable increase of

Pexpenditure per lunatic, which the Lieute. 49 and 59. nant-Governor considers is satisfactorily accounted for by the unusual and abnormal condition of things that necessitated it. The scarcity rates prevailing caused a large increase on account of diet charges in both Asylums, and in the Lahore iustitution a charge for clothing and blankets purchased in $\mathbf{1 8 9 5}$ had to be adjusted in 1896. A special expenditure sanctioned in the Government letter No. 289, dated 4th June 1896, for the purchase of stoves for the comfort of old and weak patients was also incurred. In the case of the Delhi Asylum it is stated that an excess of Rs. 242-4-11 in establishment charges over the figure for the year 1895 is due to "increase of establishment." This remark is not understood, as the letters from the Civil Secretariat noted on the \$No. 833 C., dated margin§ sanctioned revisions of establish. 23rd April 1865. No. ment which resulted in a decrease of Rs. 4 123 S., dated 6th per mensem in establishment charges. A

per mensem in establishment charges. $\mathbf{A}$ Report for the year 1896, with the similar statement in the Report for 1895, will show that effect was apparently given to this reduction, as the total cost for establishment for the year 1896 is shown as Rs. 310 per mensem against Rs. 314 in the previous year. It is also not understood why a "prisoner cook" on Rs. 5 per mensem, who was shown in the Proposition Statements attached to the correspondence connected with the letters quoted above, has not been shown in Statement $\mathbf{X}$ of the Report. The Inspector-General is requested to be so good as to obtain and submit the necessary explanations. One of the reasons for the revision oî establishment was to increase the pay of the warder establishment in view to inducing a better class of men to seek service as warders. It is stated in the Report that " the better rates of pay have enabled the Superintendent to get a somewhat better class of men' but the matter of the escapes referred to above seems to corroborate the further remark in the 